\title{
Hans Bluntschli als Morphologe
}

\author{
Rudolf Greif und Hans-Konrad Schmutz
}

\section{Summary}

The primatologist Hans Bluntschli, M. D. (1877-1962) published several papers on variations in the circulatory system of man and other primates, a description of the fossil New World monkey Homunculus patagonicus as well as works on the function of the jaw and masticatory muscles of man and apes. Caught between the conflicting views of traditional comparative and emerging experimental evolutionary biology, Bluntschli objected to new genetic theories and increasingly supported neo-Lamarckian ideas of heredity. By studying Bluntschli's articles and unpublished manuscripts one can follow the change of evolutionary concepts from the wide-spread scepticism about Darwin's theory of natural selection around 1900 up to the formulation of the Synthetic Theory of Evolution in the 1940s.

\section{Zusammenfassung}

Der Anatom und Primatologe Hans Bluntschli (1877-1962) veröffentlichte eine Reihe von phylogenetischen Arbeiten über Variationen im Gefässsystem des Menschen und anderen Primaten, eine Beschreibung des fossilen Neuweltaffen Homunculus patagonicus sowie Arbeiten über die Funktion des Kiefersystems und der Kaumuskulatur des Menschen und der Menschenaffen. Im Spannungsfeld zwischen traditionell vergleichender und aufstrebender experimenteller Evolutionsbiologie wehrte er sich gegen neue genetische Theorien und vertrat zunehmend neo-lamarckistische Vererbungsmuster. Anhand seiner Publikationen sowie unveröffentlichter Manuskripte lässt sich der Wandel der evolutionären Konzepte von der weit verbreiteten Skepsis gegenüber Darwins Selektionstheorie um 1900 bis zur Formulierung

Rudolf Greif, Oetenbachgasse 15, CH-8001 Zürich — Dr. Hans-Konrad Schmutz, Chaletweg 2, CH-8400 Winterthur 


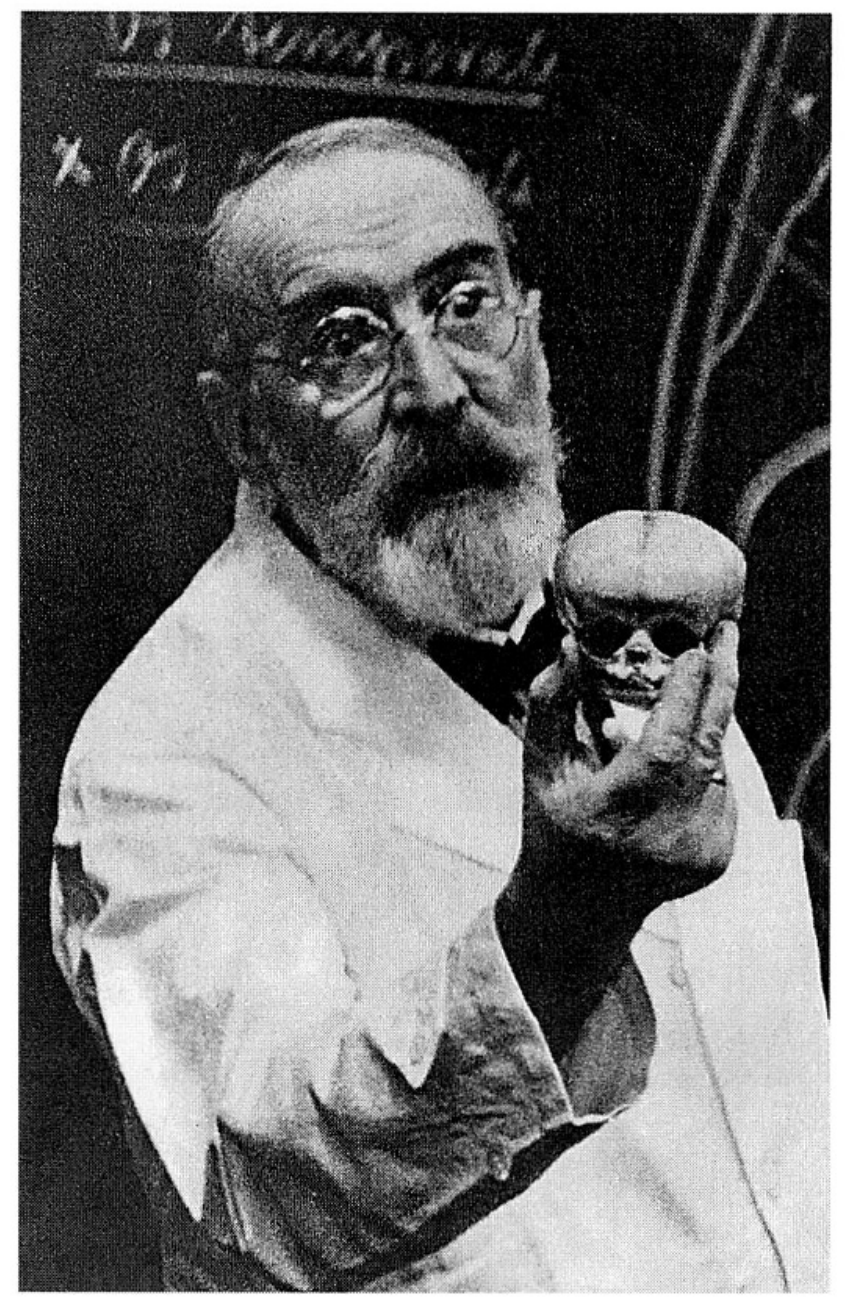

Hans Bluntschli (1877-1962)

der synthetischen Theorie der Evolution in den 1940er Jahren nachvollziehen.

Hans Bluntschli wurde am 19. Februar 1877 in Frankfurt am Main als Sohn des Architekten Alfred Friedrich Bluntschli (1842-1930) und Anna-Maria Kriegk (1856-1940) geboren. ${ }^{1} 1881$ übersiedelte die Familie nach Zürich, weil Alfred Bluntschli eine Professur an der Eidgenössischen Technischen Hochschule in Zürich (ETH) übernahm. Hans Bluntschli besuchte in Zürich die Primarschule und ab 1887 in Winterthur das Gymnasium. Der dort lehrende Botaniker Robert Keller (1854-1939) übte grossen Einfluss auf den jungen Bluntschli aus, wie Bluntschli selbst in späteren Jahren oft betonte. Keller

1 Die folgenden biographischen Angaben stützen sich - wo nicht anders erwähnt - auf: Strauss, F.: Zum Andenken an Hans Bluntschli 1877-1962. Acta anat. 58 (1964) 1-25. (Enthält ein Werkverzeichnis der publizierten Arbeiten Bluntschlis.) 
hatte in Jena studiert und war ein grosser Anhänger von Ernst Haeckels (1834-1919) zoologischen und embryologischen Theorien. 1895 begann Bluntschli in Zürich das Studium der Naturwissenschaften, unter anderem beim Zoologen Arnold Lang (1855-1914), wechselte dann aber zur Medizin über. Er studierte in Zürich, München, Leipzig und Heidelberg, wo er 1902 das ärztliche Staatsexamen ablegte. In Heidelberg lernte Bluntschli auch die vergleichende Anatomie Carl Gegenbaurs (1826-1903) näher kennen. Gegenbaur war neben Haeckel der einflussreichste damalige Morphologe und hielt in Heidelberg den wohl wichtigsten Lehrstuhl für vergleichende Anatomie inne. ${ }^{2}$ Als ein plötzlich auftretendes Ohrenleiden Bluntschlis Aussicht auf eine ärztliche Laufbahn zunichte machte, blieb er am Heidelberger Anatomischen Institut als Assistent von Gegenbaurs Nachfolger Max Fürbringer (1846-1920), um sich in die vergleichende Anatomie einzuarbeiten. Bluntschli arbeitete in dieser Zeit vor allem auch an der Seite des Anatomen Hermann Braus (1868-1924). Unter der Leitung Fürbringers entstand Bluntschlis Dissertation, eine vergleichend-anatomische Arbeit über die Leber des Lungenfisches Ceratodus forsteri. ${ }^{3}$

1904 wechselte Bluntschli ans Anatomische Institut der Universität Zürich. Unter Georg Ruge (1852-1919) war dort ein wichtiges Zentrum für vergleichende Anatomie und Primatologie entstanden. Bluntschli habilitierte sich 1906 mit einer vergleichenden Studie über Arterienvarietäten bei Altweltaffen. ${ }^{4}$ Diese und weitere Variationsarbeiten zeigten sich deutlich von Ruges Primatologie geprägt. ${ }^{5}$ Dennoch war die Beziehung des temperamentvollen Bluntschli zum ausgeglicheneren Ruge stets belastet. Unzufrieden mit seiner bisherigen wissenschaftlichen Laufbahn und bedrückt von persönlichen Problemen, erlitt Bluntschli einen schweren seelischen $\mathrm{Zu}$ sammenbruch und entschloss sich kurzfristig, die Wissenschaft aufzugeben. Nach einer Erholungspause heiratete er die Bündnerin Anna von Bavier

2 Die Begriffe 'Morphologie' 'vergleichende Anatomie' wurden zu dieser Zeit in einem weit gesteckten Rahmen verwendet: "Morphology' sometimes meant comparative anatomy, sometimes comparative anatomy and embryology, sometimes taxonomy ...» [Allen, G.: Morphology and 20th Century Biology: A Response. J. hist. biol. 2 (1969) 161.] In diesem Aufsatz beinhalten die Begriffe 'Morphologie'/'vergleichende Morphologie' immer auch embryologische Tätigkeiten, während 'Anatomie'/'vergleichende Anatomie' für Arbeiten mit ausgewachsenen Formen reserviert bleibt. Eine exakte Abgrenzung der Begriffe ist jedoch oft nicht möglich.

3 Bluntschli, H.: Der feinere Bau der Leber von Ceratodus forsteri, zugleich ein Beitrag zur vergleichenden Histologie der Fischleber. Jena Denkschr. 4 (1903) 1-41.

4 Bluntschli, H.: Die Arteria femoralis und ihre Äste bei den niederen catarrhinen Affen. Morph. Jb. 36 (1906) 276-461.

5 Bluntschli, H.: Varietäten der Arteria profunda femoris und der Arteria circumflexa femoris medialis des Menschen. Morph.Jb. 37 (1907 I) 142-154. Bluntschli, H.: Über die Asymmetrie der Sinus transversi durae matris bei Menschen und Affen. Verh. Ges. dt. Naturf. Ärzte 80 (1908) 361-362. 


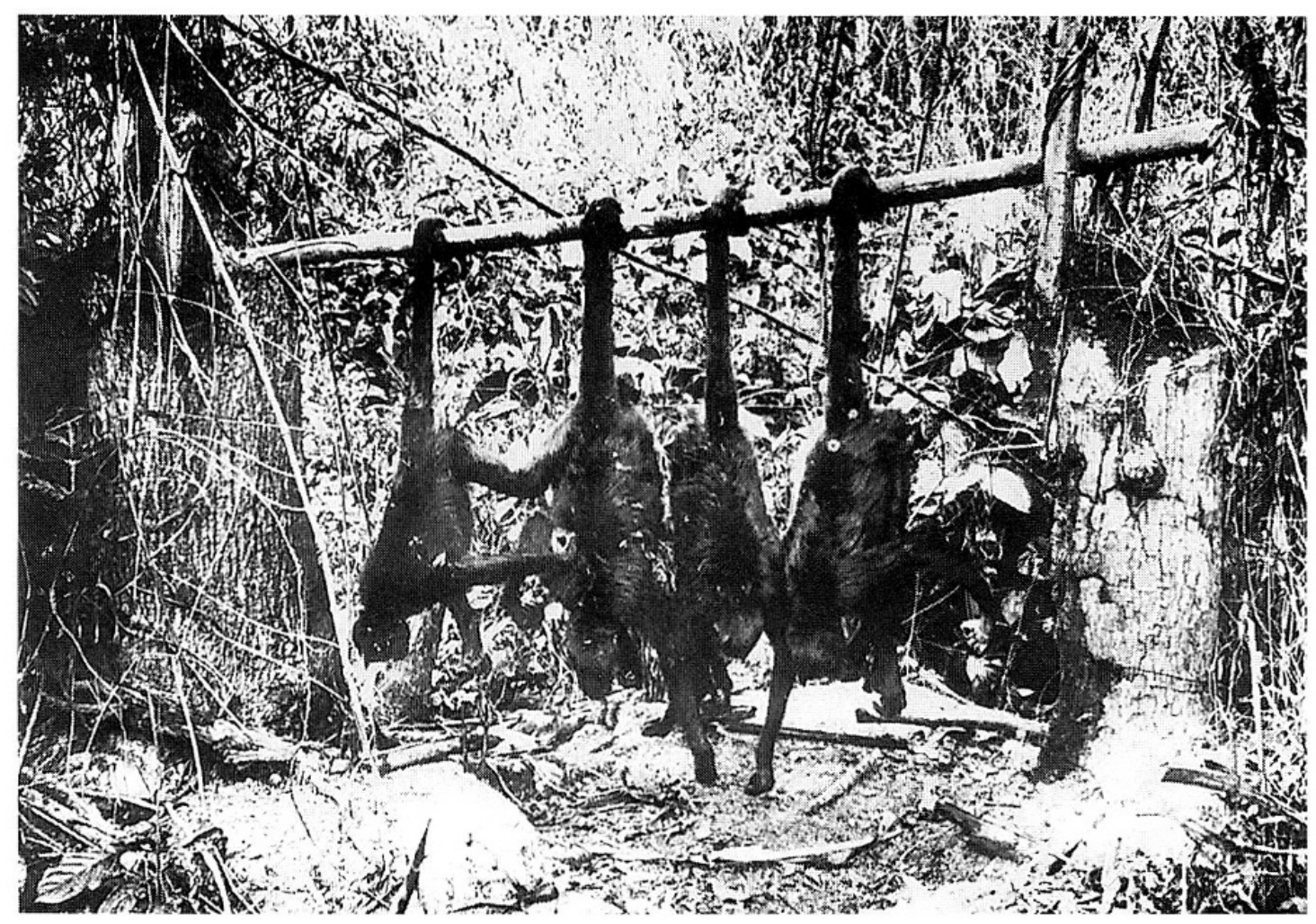

Abb. 1. Von Bluntschli erlegte Ateles-Affen im Urwald des Amazonas (Aufnahme im Besitz des anthropologischen Instituts der Universität Zürich).

(1880-1961) und wandte sich erneut der primatologischen Forschung zu. Zur Beschaffung von dazu notwendigen Primatenpräparaten organisierte er eine Expedition nach Südamerika. Zusammen mit dem Paläontologen Bernhard Peyer (1885-1963) erlegte und konservierte Bluntschli 1912/13 im Amazonasgebiet über dreihundert Affen, Fische, Reptilien und Vögel (Abb. 1). In Argentinien sichtete er zudem Fossilreste von Homunculus patagonicus im Hinblick auf deren spätere wissenschaftliche Beschreibung. Nach seiner Rückkehr weigerte sich Bluntschli, seine Sammlungsstücke dem Anatomischen Institut der Universität Zürich zur Verfügung zu stellen. ${ }^{6}$ Die latenten Spannungen mit Ruge begünstigten daher Bluntschlis Übernahme einer Prosektorenstelle am Senckenbergischen Anatomischen Institut in Frankfurt unter Ernst Göppert (1866-1945). Rasch erfolgten dort die Beförderungen zum Titularprofessor (1915), zum Abteilungsvorsteher (1918) und zum ausserordentlichen Professor (1919).

6 Die Spannungen zwischen Ruge und Bluntschli widerspiegelt eine Briefsammlung des medizinhistorischen Instituts der Universität Zürich sowie das Familienarchiv Hans Bluntschli [FA BL], Mappe 127.35. (Das Familienarchiv Hans Bluntschli ist im Besitz der Zentralbibliothek Zürich.) 


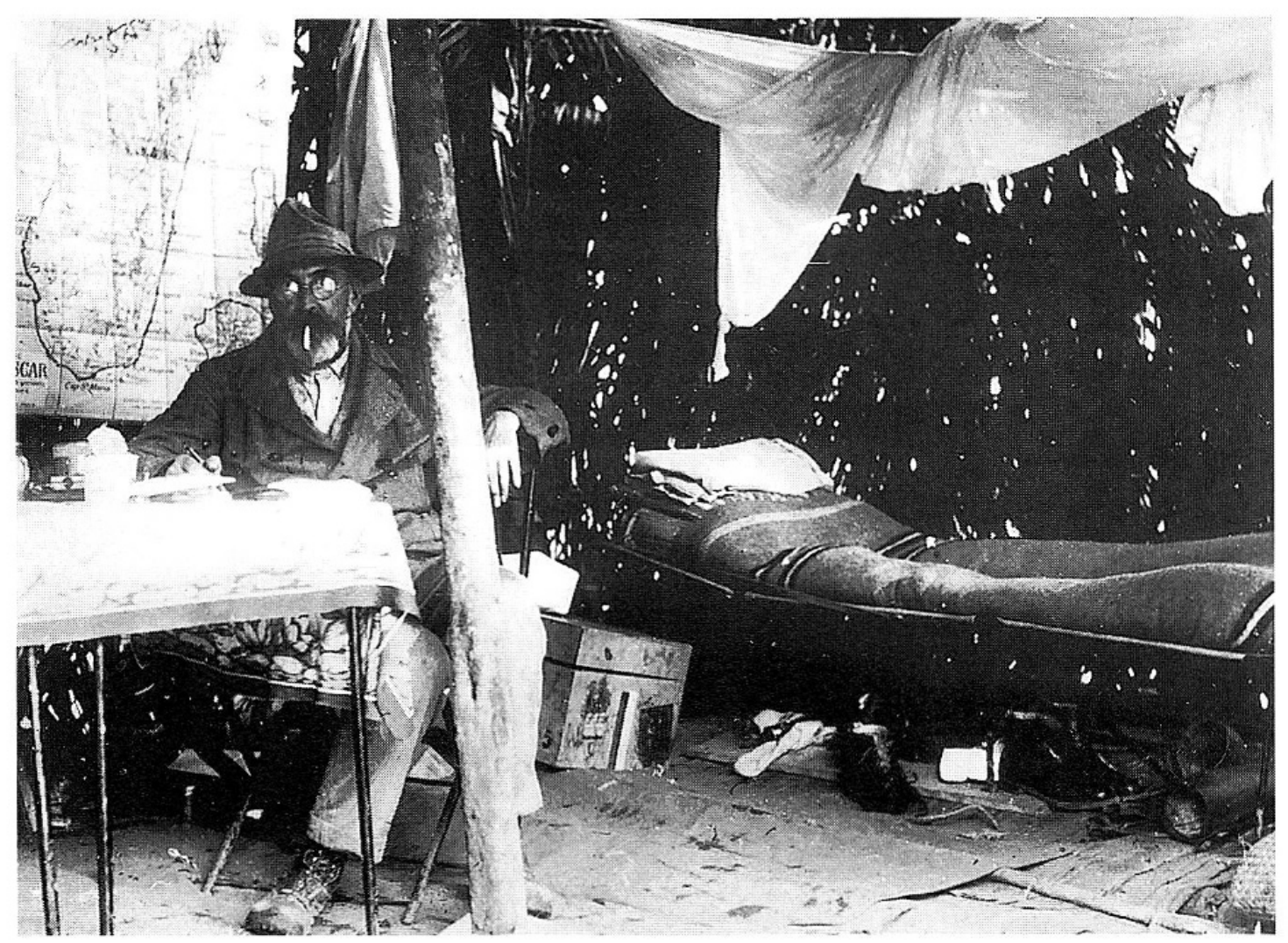

Abb. 2. Hans Bluntschli in seinem Lager auf Madagaskar (Aufnahme im Besitz des anthropologischen Instituts der Universität Zürich).

In Frankfurt war Bluntschli intensiv mit dem Aufbau des Anatomischen Instituts und damit verbundenen Lehrtätigkeiten beschäftigt. Ab Mitte der 1920er Jahre folgten weitere morphologische Arbeiten, die neu von funktionellen Analysen geprägt waren. In Begleitung seines Assistenten, des Anatomen Rudolf Brandes (geb. 1906), unternahm Bluntschli von April 1931 bis Januar 1932 eine zweite Sammlungsexpedition, diesmal nach Madagaskar (Abb. 2). Bluntschli und Brandes gelang die Sammlung einer stattlichen Anzahl von ausgewachsenen Lemuren und Lemurenembryonen.

Aufgrund seiner ausdrücklich demokratisch-pazifistischen Gesinnung wurde Bluntschli 1933 von den damaligen neuen Machthabern in Deutschland als Institutsdirektor in Frankfurt abgesetzt, während er sich an der Jahrhundertfeier der Universität Zürich in der Schweiz aufhielt. ${ }^{7}$ Doch bot ihm die Universität Bern schon auf das Wintersemester 1933/34 die Übernahme des anatomischen Lehrstuhls des zurückgetretenen Karl Wilhelm Zimmer-

7 Eine Darstellung dieser Gegebenheiten bietet Drabek, A: Die Dr. Senckenbergische Anatomie von 1914-1945. Frankfurter Beiträge zur Geschichte, Theorie und Ethik der Medizin, Band 7 (1988) 70-73 sowie Bluntschli selbst in persönlichen Aufzeichnungen. [In: FA BL, Mappe 83.] 
mann (1861-1935) an. Bluntschli hielt diesen Lehrstuhl bis zu seiner Emeritierung im Jahr 1947 inne.

Die Berner Zeit war geprägt von der Bearbeitung des gesammelten Madagaskar-Materials mit Hilfe zahlreicher Doktoranden und Schüler, Lehrtätigkeiten, politischen Aktivitäten für Flüchtlinge aus Deutschland sowie der Gründung der wissenschaftlichen Zeitschrift Bio-Morphosis. Nach 1939 nahm die Zahl von Bluntschlis wissenschaftlichen Veröffentlichungen deutlich ab. Er widmete sich in vermehrtem Mass politischen und historischen Themen und hielt häufig Vorträge im In- und Ausland. In den 1950er Jahren machte sich ein Herzleiden bemerkbar, an dem Bluntschli am 13. Juli 1962 schliesslich starb.

Die primatologischen und morphologischen Veröffentlichungen Bluntschlis fanden in der wissenschaftshistorischen Literatur bisher bereits einige Beachtung. ${ }^{8}$ Eine umfassendere Aufarbeitung von Bluntschlis morphologischen und primatologischen Arbeiten sowie seiner unveröffentlichten evolutionstheoretischen Manuskripte fehlte jedoch bislang. ${ }^{9}$

\section{Variationsuntersuchungen}

Nach der Veröffentlichung von Charles Darwins (1809-1882) Selektionstheorie im Jahre 1859 standen evolutionäre Konzepte im Mittelpunkt des Interesses der vergleichenden Morphologie. Die Mehrzahl der Morphologen interessierte sich dabei in erster Linie für die Abstammung der Arten und die Klärung der evolutiven Zusammenhänge zwischen den rezenten (lebenden) Formen, insbesondere auch des Menschen. Diese Klärung erhoffte man

8 Neben drei 1962,1963 und 1964 von seinen Schülern Dietrich Starck (geb. 1908), Fritz Strauss (1907-1994) und Erich Hintzsche (1900-1975) erschienenen Nachrufen [Starck, D.: Hans Bluntschli 1877-1962. Natur und Museum 92/9 (1962) 339-342. Hintzsche, E.: Hans Bluntschli (1877-1962). Ver. schweiz. naturforsch. Ges. 142 (1963) 195-202. Strauss 1964, 1-25] beleuchtete Alexander Drabek Bluntschlis pädagogische Arbeiten und die funktionelle Morphologie innerhalb der Senckenbergischen Anatomie in Frankfurt [Drabek 1988,40-74]. Ein kurzer Abriss von Bluntschlis wissenschaftlicher Tätigkeit, speziell an der Universität Bern, stammt von Urs Boschung [Boschung, U.: Anatomie in Bern: Ein historischer Abriss. In: Die Anatomie in Bern von 1896/97 (Festschrift zur Gesamtrenovation 1984-88). Denkmalpflege der Stadt Bern, Stämpfli \& Cie, Bern 1988, 21-37]. Im Rahmen der Zürcher medizingeschichtlichen Abhandlungen befasste sich Fatih Cener mit anatomischen und primatologischen Arbeiten von Hans Bluntschli [Cener, F.: Der Anatom Hans Bluntschli 1877-1962. Zürcher med. gesch. Abhandl. Nr. 212 (1990)], während Stefan Organ kurz auf Bluntschlis Zürcher Zeit unter Ruge einging [Organ, S.: Der Anatom und Primatologe Georg Ruge 1853-1919. Zürcher med. gesch. Abhandl. Nr. 254 (1993) 90-101].

9 Für eine ausführlichere Darstellung der vorliegenden Schrift siehe Greif, R.: Hans Bluntschli als Primatologe (Diplomarbeit). Zürich 1991. In: Bibliothek des anthrop. Instituts der Universität Zürich. 
sich durch das Aufsuchen aussagekräftiger Merkmale und ihrem gegenseitigen Vergleich. Die Methode der Wahl bestand in der Unterscheidung von homologen Teilen (welche unter jeder Bedingung gleiche Gestalt aufwiesen und somit gleiche Abstammung belegen sollten) von analogen Teilen (welche nur aufgrund funktioneller Anpassungen gleich waren und die Morphologen nicht interessierten). ${ }^{10}$

Die eine theoretische Grundlage bildete dabei das Evolutionsverständnis Carl Gegenbaurs. Die Evolution der Arten kam gemäss Gegenbaur dadurch zustande, dass sich Tiere und Pflanzen ständig neuen Umweltverhältnissen anpassten (Adaptation) und dadurch neue Merkmale erwarben. Diese Merkmale gingen mit der Zeit ins Erbgut über und wurden an die Nachkommen weitervererbt. Gegenbaur sprach von einem Prinzip der Veränderlichkeit (der Adaptation) und einem Prinzip der Konstanz (der Vererbung). ${ }^{11}$ Die ständig auftretenden kleinen Variationen, auf welchen Darwin seine Selektionstheorie aufgebaut hatte, stellten für Gegenbaur somit zweckmässige Anpassungsphänomene an neue Verhältnisse oder aber gespeicherte phylogenetisch alte Merkmale, sogenannte Atavismen, dar. Die Vererbung als konstantes Prinzip war befähigt, solch alte Merkmale bei ausgewachsenen Tieren wieder in Erscheinung treten zu lassen. Zur damaligen Zeit besass noch niemand Kenntnis von der Tätigkeit von Chromosomen und Genen, so dass die Ansicht, die Vererbung bewirke lediglich die unveränderte Speicherung und Weitergabe vorhandener Merkmale, allgemein verbreitet war.

Damit verknüpft war die andere wesentliche Grundlage der damaligen Morphologie, die Idee einer ontogenetischen Rekapitulation. Vor allem Ernst Haeckel hatte sie 1866 in seiner Generellen Morphologie des Menschen als biogenetisches Grundgesetz propagiert. Jedes Einzelindividuum wiederholte gemäss diesem Gesetz während seiner ontogenetischen (vorgeburtlichen) Entwicklung die Evolution seiner Art, indem es regelmässig die Merkmale der direkten Vorfahren (welche die Vererbung gespeichert hatte) durchlief. Embryonen waren somit für den Morphologen zum Studium der Evolution hervorragend geeignet, da man aus diesen rekapitulatorischen (palingenetischen) Merkmalen die Vorfahren selbst rekonstruieren zu können glaubte. Doch waren ontogenetische Merkmale keineswegs unproblematisch. Haeckel hatte betont, dass keine vollständige Rekapitulation stattfand. Sogenannte caenogenetische Merkmale entstanden durch Anpassung der Organismen an neue embryonale Verhältnisse und verfälschten

10 Coleman, W.: Morphology in the Evolutionary Synthesis. In: Mayr, E. \& Provine, W. B.: The Evolutionary Synthesis. Cambridge/London, 1980, 170-171. Allen 1969, 162.

11 Gegenbaur, C.: Grundriss der vergleichenden Anatomie, 2. Aufl. Von Engelmann, Leipzig, $1878,6-8$. 
so das Bild der Phylogenie. Zur Darstellung echter phylogenetischer Entwicklungslinien anhand von Embryonen mussten demnach caenogenetische von phylogenetisch bedeutsamen palingenetischen Merkmalen unterschieden werden. ${ }^{12}$

Diese Trennung erfolgte durch den Vergleich embryologischer Merkmale mit den Merkmalen der verschiedenen Tierformen. Gegenbaur hatte in seinen Grundzügen der vergleichenden Anatomie die vergleichenden Befunde sogar als Erklärung für die Phänomene der Ontogenie dargestellt. Seine Einteilung des Tierreichs in sieben Typen (von Protozoen bis zu Wirbeltieren) widerspiegelte demnach bereits den Ablauf der Evolution, und die Ontogenie jedes Individuums rekapitulierte somit diese typenhafte Einteilung. ${ }^{13}$ Gegenbaur behauptete jedoch auch, dass letztlich erst die Ontogenie mit ihren beobachtbaren Entwicklungsschritten der Beweis dafür war, dass die verschiedenen Typen des Tierreichs tatsächlich eine phylogenetische Entwicklung aufzeigten. ${ }^{14}$ Sowohl die Embryologie wie die vergleichende Anatomie belegten damit den Ablauf der Evolution und dienten zirkelschlussartig zur Begründung der jeweils anderen Wissenschaft. Erstaunlich scheint, dass zur Festlegung phylogenetischer Entwicklungslinien bisher nie Fossilien erwähnt wurden. Zur damaligen Zeit waren jedoch erst wenige Funde bekannt; die Bedeutung von fossilen Belegen wurde zudem von vielen Wissenschaftlern (an ihrer Spitze Ernst Haeckel) als gering erachtet. ${ }^{15}$

Die erwähnten ersten wissenschaftlichen Arbeiten Bluntschlis in Zürich (s. Anm. 4 und 5) lehnten sich deutlich an die Primatologie Georg Ruges an. Ruge war ein Schüler Gegenbaurs und Haeckels und wandte deren vergleichende Methodik in einer Reihe von Arbeiten auf die Primaten an zur Klärung von verwandtschaftlichen Verhältnissen, insbesondere auch der Abstammung des Menschen. Seine Studien beinhalteten neben Primaten auch Säugetiere, vergleichendend-embryologische Befunde sowie Variationssammlungen bei Menschen und anderen Primaten. ${ }^{16}$

1909 erschien im Morphologischen Jahrbuch Bluntschlis erste eigenständigere grössere Arbeit: «Beiträge zur Kenntnis der Variation des Menschen». ${ }^{17}$ Sie enthielt Beschreibungen einer Sammlung von Variationen

12 Haeckel, E.: Generelle Morphologie der Organismen, Bd. 2. Reimer, Berlin, 1866, 300. Gould,

S. J.: Ontogeny and Phylogeny. Belknap Press of Harvard Univ., Cambridge/London, 1977, $76,81,82$.

13 Gegenbaur 1878, 6.

14 Gegenbaur 1878,6. Gegenbaur, C.: Ontogenie und Anatomie in ihren Wechselbeziehungen betrachtet. Gegenbaurs Morph. Jb. 15 (1889) 4.

15 Schmutz, H. K.: Hypothetische Bindeglieder zwischen Affe und Mensch. Sudhoffs Arch. 68 (1984) Heft 1,82.

16 Maurer, F.: Georg Ruge. Anat. Anz. 54 (1921) 24-26.

17 Bluntschli, H.: Beiträge zur Kenntnis der Variation beim Menschen I und II. Morph. Jb. 40 (1909 I) 195-261. 
menschlicher Präparate und eine Klassifizierung der Variationen in verschiedene Variationstypen. Bluntschli unterschied atavistische von oszillatorischen und embryonal-adaptiven Variationen und bemühte sich dabei um die Kennzeichnung von phylogenetisch bedeutsamen Merkmalen. Doch löste er sich bereits vom Verständnis Gegenbaurs und Ruges. Die Kiemen- und Schwanzbildungen bei menschlichen Embryonen waren zwar auch für Bluntschli Kennzeichen früherer evolutiver Epochen. Diese atavistischen Strukturen machten für ihn eine Abstammung des Menschen von schwanztragenden Tierformen wahrscheinlich. ${ }^{18}$ In einer Variation mit einem doppelten Aortenbogen dagegen erkannte Bluntschli zwar vogel- und reptilienähnliche Merkmale, entlarvte sie aber als Scheinatavismus. Sie war kein durch Vererbung hervorgerufenes phylogenetisch altes Merkmal, sondern eine durch Anpassung an embryonale Verhältnisse entstandene embryonal-adaptive Variation und entsprach somit von Haeckel beschriebenen caenogenetischen Merkmalen:

"Wie könnte ein Vogelzustand ein Atavismus für Säugetiere darstellen, wo diese doch nie durch ein Vogelstadium durchgegangen sind, wie könnte das Stadium A [die Variation mit doppeltem Aortenbogen] ein Atavismus auf Reptilbefunde sein, da doch eine vollständige Scheidung des grossen und kleinen Kreislaufs, wie hier, bei keinem Kaltblütler besteht." ${ }^{19}$

Eine Reihe von Befunden mit 11 oder 13 Rippen beim Menschen beschrieb Bluntschli schliesslich als oszillatorische Variation. Als Variationsreihe stellten sie einen evolutiven Vorgang nur in dem Sinne dar, dass die eine Hälfte der Variationen atavistische Merkmale waren, die andere Hälfte jedoch neue, «gleichsam tastende Versuche der Natur». ${ }^{20}$ Die Technik der Aufstellung von Variationsreihen hatte schon Ruge in verschiedenen Arbeiten aufgezeigt, doch war sie von ihm immer streng zur Darstellung bereits bekannter evolutiver Phänomene (wie etwa der Aufrichtung des Körpers) verwendet worden. ${ }^{21}$ Bluntschli hingegen begann seine Variationsreihen auch theoretisch zu durchleuchten. Die Variationen, so zeigte er anhand der Reihen, oszillierten um die Norm der Art und besassen - im Gegensatz zum Verständnis Gegenbaurs - einen zumindest teilweise zufälligen Charakter. ${ }^{22}$

18 Bluntschli, H.: Der Mensch als Primate [DMAP] (1909/10) Kap. IV (Entwicklung 2) 49 (Unveröffentlichtes Manuskript). In: Schachtel 'Primaten-Studien II'. Im Besitz des anthrop. Instituts der Universität Zürich.

19 Bluntschli, H.: Über die individuelle Variation im menschlichen Körper und ihre Beziehungen zur Stammesgeschichte. Quelle und Meier, Leipzig, 1910, 24, 28.

20 Bluntschli, H.: Das Gebiss des Menschen als Zeugnis seiner Vergangenheit. Wissen und Leben 1 (1907 II) 2. Bluntschli 1910, 12.

21 Ruge, G.: Beiträge zur Gefässlehre des Menschen. Morph.Jb. 9 (1884) 329-388. Ruge, G.: Varietäten im Gebiete der Arteria femoralis des Menschen. Morph. Jb. 22 (1895) 161-224.

22 Bluntschli 1910,12-13. 


\section{Der eigentliche Darwinismus}

Auf der Grundlage der morphologischen Befunde legte Bluntschli in den «Beiträgen zur Kenntnis der Variation des Menschen» auch seine frühen evolutionstheoretischen Ansichten dar. Das Phänomen der Variabilität bildete weiterhin den Kernpunkt sowohl für Bluntschli wie für die gesamten biologischen Wissenschaften. ${ }^{23}$ Darwin hatte angenommen, dass Variationen häufig vorkamen, zweckmässig oder unzweckmässig jeden Merkmalskomplex abzuändern vermochten und auf die Nachkommen vererbt wurden. Den Ursprung der Variationen hatte er jedoch nicht erklären können. So durchzogen Zweifel an der Zweckmässigkeit zufälliger Variationen die Wissenschaft. Viele Morphologen konnten sich nicht vorstellen, wie neue Arten aus nur zufälligen, geringfügigen und oft unzweckmässigen Variationen hervorgehen sollten. ${ }^{24}$

Um 1900 bestand innerhalb der biologischen Wissenschaften kein allgemein akzeptierter, dem heutigen Verständnis gleichkommender kausaler Zusammenhang zwischen Vererbungsmechanismen und Variationen im Körperbau. Der Freiburger Zoologe August Weismann (1834-1914) war 1892 der erste Wissenschaftler gewesen, welcher Variationen aus der Tätigkeit von Vererbungsfaktoren zu erklären versucht hatte. Weismann hatte neben einem sichtbaren Körperplasma in jeder Zelle ein Keimplasma postuliert. Dieses Keimplasma war einerseits für die Entwicklung des Körpers verantwortlich, vermischte sich andererseits bei jedem Befruchtungsvorgang mit dem Keimplasma eines zweiten Organismus und war aufgrund gewisser Unregelmässigkeiten bei diesen Vorgängen auch für die morphologischen Variationen verantwortlich. Weismann konnte keine empirischen Belege für die Existenz des Keimplasmas und seiner Bestandteile erbringen, doch nahm er mit seiner Theorie die ungefähre Funktionsweise der Chromosomen und Gene bereits vorweg. ${ }^{25}$

Bluntschli bezeichnete die Variabilität als eine grundlegende Eigenschaft des menschlichen Organismus, Zeichen einer allgemeinen Wandlungsfähigkeit des Körpers. ${ }^{26}$ Diese Wandlungsfähigkeit erinnert zunächst deutlich an das Evolutionsverständnis Carl Gegenbaurs, das in alten Merkmalen nur das Wirken von Vererbung, in neuen Merkmalen Anpassungsphänomene sah. In einer Publikation über Variationen folgerte Bluntschli 1910 nämlich, dass die

23 Bluntschli 1909 I, 197.

24 Bowler, P.: Evolution. The History of an Idea. London, 1989, 208.

25 Bowler 1989, 251.

26 Bluntschli, H.: Einführung in die Lehre von der Abstammung des Menschen. Zürich, 1909 II, 3,6 . 
um die Norm der Art oszillierenden Variationen sich nicht mehr ausbilden würden, falls ein Organismus sich vollständig seiner Umwelt angepasst hätte, die Variabilität also zum Stillstand käme. ${ }^{27}$ Trotzdem sah sich Bluntschli bei anderen oszillatorischen Variationen im Processus entepicondylus und der Gesichtsmuskulatur des Menschen

«zu dem Schluss gedrängt, dass diese Varianten von vornherein als solche angelegt werden und deshalb nichts anderes sind als die morphologischen Manifestationen einer sog. Keimesvariation im Sinne Weismanns.» ${ }^{28}$

Neben den durch Adaptation hervorgerufenen, äusserlich bewirkten Variationen vermochte sich Bluntschli damit vorzustellen,

«... dass ohne äussere Einflüsse auch selbständige Keimesvariationen, gleichsam zufällig sich einstellen könnten.» ${ }^{29}$

Die Variabilität war für Bluntschli somit sowohl ein zufälliger wie auch ein gerichteter Prozess.

In der Wirkung von Selektionsmechanismen sah Bluntschli eine weitere zufällige Komponente im Evolutionsgeschehen. ${ }^{30}$ Wie bei den Variationen schieden sich dabei die Meinungen an der Frage der Zweckmässigkeit. Es wurde bezweifelt, dass ungerichtete Prozesse wie Weismanns Keimesvariationen und die darwinsche Selektion wirklich zweckmässige, besser an die Umwelt angepasste Arten hervorbringen konnten. Zweckmässigkeit schien am ehesten durch die Adaption gewährleistet zu sein: morphologische Abänderungen auf eine bestimmte Anpassungsleistung hin gerichtet. ${ }^{31}$ Bluntschli jedoch ging davon aus, dass nur eine relative Zweckmässigkeit der Merkmale gefordert werden dürfe, da auch die bestehenden Arten nicht absolut zweckmässig seien. ${ }^{32}$ Adaptations- und Selektionsmechanismen standen in seinem Verständnis in keinem Widerspruch zueinander.

Auch andere Wissenschaftler bemühten sich um eine Annäherung von Selektions- und Adaptationsphänomenen. Der Morphologe Wilhelm Roux (1850-1924), ein Schüler Ernst Haeckels, hatte 1881 in seinem Buch Der Kampf der Theile im Organismus zu versuchen belegt, wie sich Selektionsphänomene innerhalb jedes Organismus durch Selbstregulation abspielten. Gewisse Reize der Umwelt förderten die Ernährung der Zellen mehr als an-

27 Bluntschli 1910, 28, 29.

28 Bluntschli 1910, 27.

29 Bluntschli DMAP, Kap. VI (Vererbung) 62.

30 Bluntschli 1909 II, 7. Bluntschli DMAP, Kap VI (Vererbung) 61-62.

31 Bowler 1989,208. Ghiselin, M.:The Failure of Morphology to Assimilate Darwinism. In:Mayr, E. \& Provine,W. B.: The Evolutionary Synthesis. Cambridge/London, 1980, 184. Montgomery, W.: Germany. In: Glick (Hrsg.): The Comparative Reception of Darwinism. Austin/London, $1974,115$.

32 Bluntschli 1910, 28. 
dere Reize. Unter den Zellen begann sich ein Kampf um Ernährungssubstanzen (vergleichbar dem darwinschen Kampf ums Dasein) abzuspielen, in dem sich schliesslich jene Gewebe durchsetzten, welche sich schneller als andere vermehrten. Sie waren demzufolge aufgrund der Selektionsphänomene im Inneren dauerhafter und zweckmässiger. ${ }^{33}$

Für Bluntschli war die rouxsche Selektionstheorie Beweis nicht für das Wirken der natürlichen Selektion, sondern ein Beleg für Adaptationsmechanismen. So sah er die definitive Ausgestaltung der teilweise zufälligen embryonal-adaptiven Variationen durch die rouxschen Mechanismen bestimmt. ${ }^{34}$

Schliesslich bildete die Vererbung ein weiteres wichtiges Thema in Bluntschlis frühem Evolutionsverständnis. Er hob dabei hervor, wie wenig der damaligen Biologie von Vererbungsmechanismen bekannt war. ${ }^{35}$ Weismanns Keimplasmatheorie war spekulativ geblieben. Viele lehnten sie strikte ab und sahen in der Vererbung nach wie vor einen «harten» Mechanismus nur zur unveränderlichen Weitergabe vorhandener Merkmale - ein konstantes Prinzip im Sinne Gegenbaurs. ${ }^{36}$ Gemäss diesem Verständnis wurde für Bluntschli das Phänomen der Vererbung an der Tatsache ersichtlich, dass bestimmte Variationen nur in bestimmten Familien und Rassen auftraten. ${ }^{37}$ Vererbung sorgte durch Konservierung der Merkmale dafür, dass die unterschiedliche Verteilung der Variationen in einer Population aufrechterhalten wurde. Bluntschli führte unter dem Stichwort Vererbung auch die mendelschen Gesetze an. ${ }^{38}$ Der holländische Botaniker Hugo de Vries (1848-1935) hatte die Resultate der heute berühmten Kreuzungsexperimente des Augustinerabts Gregor Mendel (1822-1884) 1900 erneut veröffentlicht, nachdem sie nach der ersten Publikation von 1866 in Vergessenheit geraten waren. Die mendelschen Gesetze bewiesen die Existenz von Erbfaktoren und zeigten auf, wie diese berechenbar und anscheinend unverändert weitergegeben wurden. Sie stützten damit das Bild der harten Vererbung. ${ }^{39}$

Die Variationen stellten die Theorie der harten Vererbung jedoch vor ein grosses Problem: falls sie durch Anpassungsleistungen erworben wurden (was die meisten Morphologen bejahten), waren sie nicht in den Erbanlagen vorhanden gewesen. Sie mussten jedoch später Bestandteil der Erbanlagen sein, weil sie an die Nachkommen weitergegeben wurden. Dies bedeutete

33 Roux, W.: Der Kampf der Theile im Organismus. Engelmann, Leipzig, 1881, 1-244.

34 Bluntschli 1910, 26.

35 Bluntschli 1910, 29.

36 Bowler 1989, 208, 209, 270-274.

37 Bluntschli 1909 II, 6.

38 Bluntschli 1910, 29.

39 Bowler 1989, 274-277. 
eine Vererbung erworbener Eigenschaften im lamarckistischen Sinn. Die lamarckistische Vererbung war zwar unpopulär geworden, doch zeigten sich viele Wissenschaftler angesichts der vielen ungelösten Probleme in dieser Frage unentschieden. Auch Darwin hatte 1868 eine sogenannte PangenesisVererbung entworfen, nachdem er nicht plausibel hatte klären können, ob Variationen in einer Population erhalten blieben. Gemäss Darwins Pangenesis führte jeder Körperteil den Reproduktionsorganen (in welchen die Erbanlagen gespeichert sein mussten) kleine Partikel zu. Diese Partikel veränderten dann die Erbanlagen. ${ }^{40}$

Bluntschli trat der Frage der Vererbung erworbener Eigenschaften bejahend, wenn auch etwas zurückhaltend gegenüber. In einem Manuskript zu einem geplanten umfassenden primatologischen Werk «Der Mensch als Primate» sprach er von der Verbindung zwischen Körperzellen und Keimzellen durch die Körpersäfte. Neue Eigenschaften der Körperzellen wurden durch die Körpersäfte den Keimzellen übermittelt und veränderten so die Eigenschaften der Keimzellen. Erworbene Veränderungen wurde demgemäss erblich. ${ }^{41}$

Bluntschlis Mechanismus der Körpersäfte von 1910 erinnert an Darwins Pangenesis-Theorie und weist angesichts von Weismanns Keimplasmatheorie und den Mutationstheorien (welche gemäss de Vries besagten, dass die Evolution der Arten durch plötzliche Mutationsschübe bestimmt werde) eine altertümliche Färbung auf. Das Spektrum der Evolutionstheorien um 1900 jedoch war breit, und jede Richtung zeigte die Tendenz, die andere zu negieren und die Evolution möglichst auf ein einziges Phänomen zu reduzieren. Weismann und ein Kreis von Neo-Darwinisten sahen die Evolution nur aufgrund von Vererbungsmechanismen und der natürlichen Selektion bestimmt, Neo-Lamarckisten beharrten ausschliesslich auf der Adaptation und der Vererbung erworbener Eigenschaften. Andere glaubten ausschliesslich an die plötzlichen Mutationen und wieder andere nur an die mendelschen Gesetze als Evolutionsfaktor. ${ }^{42}$ Bluntschli schlug sich keiner der genannten Richtungen ausschliesslich zu. Weder lehnte er die natürliche Selektion vollständig ab, noch bestritt er eine Vererbung erworbener Eigenschaften. Für ihn bestand in der Gültigkeit beider Prinzipien der eigentliche Darwinismus. ${ }^{43}$

40 Bowler, 1989, 209-210.

41 Bluntschli DMAP, Kap. VI (Vererbung) 62.

42 Allen 1969, 161.

43 Bluntschli 1909 II, 7. Bluntschli DMAP, Kap. VI (Vererbung) 64. 


\section{Von der vergleichenden zur funktionellen Morphologie}

Mit seiner Loslösung von der rein vergleichenden Methodik bildete Bluntschli keineswegs eine Ausnahme. Zu Beginn des 20. Jahrhunderts wandten sich viele, vor allem jüngere Morphologen, welche noch in der Tradition von Haeckel und Gegenbaur ausgebildet worden waren, von der bisherigen Morphologie ab. Zum einen frustrierte sie die zirkelschlussartige und spekulative Methodik, zum anderen die als einseitig empfundene Betonung phylogenetischer Probleme. ${ }^{44}$ Der erwähnte Wilhelm Roux hatte 1895 mit einer Reihe von Experimenten an Froscheiern die Embryologie revolutioniert. Er bezeichnete das Experiment als den einzig sicheren Weg zur Erkenntnis und nannte seine neue Methode Entwicklungsmechanik. Diese empirisch-experimentelle Forschung legte mehr Gewicht auf funktionelle Anpassungen und physiologische Prozesse als auf phylogenetische Durchdringung der Ontogenie. Roux hatte äussere Einflüsse auf die Eientwicklung wie Gravitation, Licht etc. ausgeschaltet und in Defektversuchen die Hälfte des Eimaterials zerstört. Als Ergebnis hatte er halbe Embryonen, welche nur die Hälfte der Merkmale aufwiesen, erhalten..$^{45}$

Bluntschli zeigte sich von Rouxs Experimenten beeindruckt und schlug dem medizinischen Nobelpreiskomitee 1923 in einem Brief sogar vor, Wilhelm Roux den Nobelpreis für Medizin und Physiologie zu verleihen ${ }^{46}$ Trotzdem distanzierte er sich von der rein experimentellen Forschung und charakterisierte sich weiterhin als vergleichenden Wissenschaftler:

«Wie die experimentellen Zoologen die Entwickelung und Variabilität der niederen Tiere unter natürlichen und künstlichen Einflüssen studieren u. darin einen Weg zur Erkenntnis sehen, so liegt uns Anatomen, die noch grosse u. nur von Wenigen zur Zeit als bedeutsam erkannte Aufgabe ob die Fülle der Variationen im Körperbau des Menschen zu sammeln und wissenschaftlich zu verwerten.» ${ }^{47}$

Anstelle von neuen Variationsarbeiten folgten jedoch zwei primatologische Untersuchungen. In der einen bildete ein Makakenkadaver mit einem durch Krankheit deformierten Becken den Ausgangspunkt für ausgedehnte Untersuchungen der Anatomie, Physiologie und der Bewegungsmechanik im Vergleich mit ähnlich deformierten und gesunden menschlichen Becken.

44 Allen 1969, 164 und Gould 1977, 169.

45 Querner, H.: Die Entwicklungsmechanik Wilhelm Roux' und ihre Bedeutung in seiner Zeit. In: Mann, G. \& Winau, R.: Medizin, Naturwissenschaft und Technik und das 2. Kaiserreich. Vorträge eines Kongresses in Bad Nauheim 6.-11.9.1973, 191-193.

46 Brief von Hans Bluntschli an das medizinische Nobelpreiskomitee vom 23.1.1923. In: FA BL, Mappe 27.

47 Bluntschli, H.: Das menschliche Antlitz im Lichte der vergleichenden Anatomie u. Entwickelungsgeschichte (23.1.1909), S. 6a (Ungedrucktes Vortragsmanuskript). In: FA BL, Mappe 91. 
Bluntschli gelangte zum Schluss, dass die Unterschiede zwischen den missgebildeten Affen- und Menschenbecken geringer waren als zwischen den gesunden Becken und folgerte daraus, dass sich der Mensch bezüglich der Statik des Rumpfs leichter von kletternden Primaten als von langarmigen Menschenaffen ableiten lässt. ${ }^{48}$ Diese Schlussfolgerungen Bluntschlis von 1911 entsprechen der neuen Lehrmeinung der zeitgenössischen Primatologie.

In «Das Gebiss der Platyrrhinen und seine Bedeutung für die Stammesgeschichte der Primaten» bestätigte Bluntschli durch eigene funktionelle Untersuchungen die evolutive Ableitung des Gebisses der Altweltaffen aus jenem der Neuweltaffen. Der holländische Mediziner Ludwig Bolk (1866-1930), ein ehemaliger Assistent Georg Ruges, hatte sie 1907 und 1910 veröffentlicht. ${ }^{49}$ An einem sogenannten Jochbogenmodell des Primatenschädels stellte Bluntschli alle wirkenden Kaudrucke von den Zähnen auf den Schädel, insbesondere auf den Jochbogen, dar. Damit sollte die Umwandlung von Milchzähnen in Dauerzähne durch mechanische Druckeinwirkung, besonders durch einen Verschiebungsvorgang der Zahnreihe gegen den Jochbogen während der ontogenetischen Entwicklung, verdeutlicht werden. Die vergleichende Untersuchung der Jochbogen von Primaten zeigte dann, dass derselbe Druckmechanismus, welcher für die Umwandlung der Milchzähne in Dauerzähne verantwortlich war, auch in der evolutiven Umgestaltung der Zähne der Altweltaffen aus jenen der Neuweltaffen die entscheidende Rolle spielte. $^{50}$

Obwohl die primatologischen Arbeiten von 1911 mit ihrer Betonung physiologischer und funktioneller Gesichtspunkte sich weiter von der Morphologie Gegenbaurs und Ruges absetzten, blieb doch eine Verbindung mit evolutionären Themen erhalten. Die funktionellen Modelle wurden durch vergleichend-anatomische Untersuchungen ergänzt und dienten Bluntschli weiterhin dazu, phylogenetische Problemstellungen zu klären. Auch die im folgenden Jahr begonnene Expedition nach Südamerika macht deutlich, dass sich Bluntschli nach wie vor für traditionelle Morphologie interessierte. In Briefen, Manuskripten und Aufsätzen erwähnte er die angestrebte Sammlung von Primaten als notwendig für vergleichend-anatomische wie vergleichend-embryologische Forschungen. In Argentinien strebte er zudem die

48 Bluntschli, H.: Über ein Naegele-Becken bei Macacus cynomolgus und das übrige Knochengerüst dieses Tieres nebst Bemerkungen über die Eigenform der Wirbelsäule und ihre mechanische Bedeutung. Morph. Jb. 43 (1911 I) 297-333.

49 Bolk, L.: Die Differenzierung des Primatengebisses. Petrus Camper, Bd. 4 (1907). Bolk, L.: Phylogenese des Primatengebisses und Zukunftsgebiss des Menschen. Zeitschr. Morph. Anthrop. 13 (1910) 31-56.

50 Bluntschli, H.: Das Platyrrhinengebiss und die Bolksche Hypothese von der Stammesgeschichte des Primatengebisses. Anat. Anz. 38 Erg.-H. (1911 II) 120-136. 
Sichtung des fossilen Neuweltaffen Homunculus patagonicus für eine morphologische Beschreibung an. ${ }^{51}$

\section{Neovitalistische Tendenzen}

Mit der Veröffentlichung von The Mechanism of Mendelian Inheritance 1915 durch den amerikanischen Zoologen Thomas Hunt Morgan (1866-1945) erhielten die bestehenden Vererbungsansichten neue Impulse. Durch Experimente mit der Fruchtfliege Drosophila konnte Morgan zeigen, weshalb die Vererbung nach mendelschen Gesetzen ablief. Er wies Chromosomen und chromosomale Mechanismen innerhalb des Zellkerns nach und identifizierte Weismanns Keimplasma als Bestandteil des Chromosoms. Weil aber auch Morgan Gene weiterhin als voneinander unabhängige Einheiten betrachtete, sah er keinen Zusammenhang zwischen den Rekombinationsmechanismen innerhalb der Chromosomen und sichtbaren morphologischen Variationen. Variationen mussten daher die Folge von Mutationen sein. ${ }^{52}$

Morgans neue Begrifflichkeit zeigte sich bald auch bei Bluntschli, der mittlerweile in Frankfurt tätig war. In Manuskripten zu 1915 gehaltenen Embryologievorlesungen schrieb er erstmals von Genen als an Chromosomen gebundene Erbfaktoren und stellte die Dominanz und Rezessivität der Gene, aber auch ihre Unabhängigkeit voneinander vor. Auch Bluntschli boten die mendelschen Gesetze damit keine Erklärung für das Auftreten von neuen morphologischen Merkmalen. ${ }^{53}$ Die Erbmasse selbst musste befähigt sein, Variationen hervorzubringen. Bluntschli zweifelte jedoch, ob solch spontanen Änderungen des Erbguts (er sprach an dieser Stelle wieder von Keimplasma im weismannschen Sinn) genügende Zweckmässigkeit zukam:

«Wir sehen heute so, dass wir sagen müssen, eine Vererbbarkeit erworbener Eigenschaften ist nicht bewiesen, aber sie muss in irgend einer Art u. Weise, u. zwar wohl nur innert bestimmter Grenzen vorkommen, da sonst ein Fortentwickeln, das Auftreten von Neuem, Besserem im organischen Werden undenkbar würde.» ${ }^{54}$

Den Mechanismus einer solchen Vererbung stellte sich Bluntschli grundsätzlich gleich vor wie 1910 die Einwirkung von Körpersäften auf die Keimzel-

51 Brief von Bluntschli an Geheimrat Waldmeyer (wissenschaftlicher Sekretär der königlichen Akademie der Wissenschaften) vom 15.1.1911. In: FA BL, Mappe 160.5.

52 Bowler 1989, 279-280.

53 Bluntschli, H.: Einige Ergebnisse der experimentellen Vererbungslehre (1915) Exp. 13Exp. 22 (Ungedrucktes Vorlesungsmanuskript). In: Mappe 'Embryologie 2'. Im Besitz des anthrop. Instituts der Universität Zürich.

54 Bluntschli, H.: Allgemeine und spezielle Entwicklungsgeschichte [ASE] (1915) 13 (Ungedrucktes Vorlesungsmanuskript). In: Mappe 'Embryologie 1'. Im Besitz des anthrop. Instituts der Universität Zürich. 
len. Da alle Zellen in ständigem physikalisch-chemischem Austausch stehen, findet eine Reiz- oder Stoffübermittlung von den Körper- auf die Keimzellen statt und macht Erwerbungen der Körperzellen erblich. ${ }^{55}$

Neben der Genetik sprach Bluntschli in seinen Vorlesungen in Frankfurt auch über die Ergebnisse der experimentellen Embryologie, besonders über Wilhelm Rouxs entwicklungsmechanische Experimente an Froscheiern. Roux hatte aus seinen Defektversuchen gefolgert, dass die Entwicklung eine sogenannte Selbstdifferenzierung sei und unabhängig von äusseren Einflüssen vor sich gehe, unter einer vorgegebenen Verteilung der Bildungssubstanzen im befruchteten Ei. Ein Organismus war somit bereits mit der ersten Zelle vorgebildet oder prädestiniert. ${ }^{56}$ Morgans neue Chromosomenbefunde stützten damit die rouxsche Entwicklungstheorie.

Rouxs Versuche waren jedoch nicht unumstritten geblieben. Der Zoologe Hans Driesch (1867-1941) hatte sie mit Seeigeleiern wiederholt, als Ergebnis jedoch keine Halbembryonen, sondern verkleinerte, mit allen Merkmalen ausgestattete ganze Embryonen erhalten. Driesch interpretierte die Entwicklung daher als Epigenese, Entwicklung in Wechselwirkung mit äusseren Faktoren. Er behauptete, dass die reine physikalisch-chemische Beschreibung den Embryo nicht zu erklären vermochte. Eine gestaltende, harmonische Kraft bewirke die Entstehung vollständiger Embryonen nach der Abtötung der einen Eihälfte. Den Keim sah Driesch als exakt abgestimmtes harmonisch-äquipotentielles System. Seine Lehre widersprach der mechanistischen, nach physikalisch-chemischen Grundsätzen fundierten Biologie und zeigte eine deutlich naturphilosophische, neovitalistische Färbung. ${ }^{57}$

Bluntschli wandte sich in seinen Manuskripten gegen eine Präformation der Organismen und eine Entwicklung ohne äussere Beeinflussung. Er lehnte die Reduktion von Entwicklungsphänomenen auf physikalisch-chemische Faktoren ab und sah in Rouxs Entwicklungsmechanik keine vollständige, neue Wissenschaft, sondern lediglich eine Methode zur Erweiterung der traditionellen Morphologie..$^{58}$ Entwicklungsvorgänge waren für Bluntschli vor allem durch äussere Einflüsse geprägt, wobei verschiedene Potenzen im Ei in harmonischer Übereinstimmung auf solche Einflüsse reagierten und aus halben Seeigeleiern ganze Embryonen konstituierten ${ }^{59}$ In

55 Bluntschli ASE, 13.

56 Querner 1973, 191-194. Die Auseinandersetzung zwischen Präformations- und epigenetischen Lehren wurde vor allem im 18. Jahrhundert geführt [Jahn, L., Löther, R. \& Senglaub, K. (ed.): Geschichte der Biologie, 2. Aufl. Gustav Fischer, Jena, 1985, 230-249.]

57 Querner 1973, 195-196.

58 Bluntschli, H.: Wilhelm Roux. Frankfurter Zeitung 717 (25.9.1924).

59 Bluntschli DMAP, 7. Bluntschli, H.: Ein Überblick über einige Grundfragen der exp. Entw. geschichte [GEE] (1915) S. Exp. 7 (Ungedrucktes Vorlesungsmanuskript). In: Mappe 'Embryologie 2'. Im Besitz des anthrop. Instituts der Universität Zürich. 
Bluntschlis Vorlesungsmanuskripten tauchen damit neovitalistische Begriffe auf, die deutlich an Driesch erinnern. ${ }^{60}$

\section{Das Basalbogensystem und neo-lamarckistische Vererbung}

In den 1920er Jahren in Frankfurt äusserte Bluntschli erneute, verstärkte Kritik an der traditionellen Morphologie. Er erkannte, dass die vergleichenden Anatomen ein zirkelschlussartiges Verfahren anwendeten,

«... da wir sagen: Homolog ist was in gleicher, auf gemeinsamer Abstammung basierender Weise entstand $u$. aus den Homologien wieder die Abstammungsgemeinschaft beweisen wollen $»^{61}$

In neuen wissenschaftlichen Projekten wandte sich Bluntschli vermehrt der Ausarbeitung funktioneller Entwicklungsfaktoren zu. Er konzipierte ein anatomisches Lehrbuch, das die gesamte menschliche Anatomie unter funktionellen Gesichtspunkten darstellen sollte. Doch kam ihm sein Heidelberger Lehrer Hermann Braus 1921 mit seiner Anatomie des Menschen, einem ebensolchen funktionellen Werk, zuvor. ${ }^{62}$ Bluntschli stellte die Arbeiten an seinem Buch ein ${ }^{63}$ und überschrieb weitere funktionelle Arbeiten Ende der 1920er Jahre und zu Beginn der 1930er Jahre folgendermassen:

«Es schwebt mir also eine Behandlungsweise als Aufgabe vor, wie sie der unvergessliche Hermann Braus in seinem leider unvollendet gebliebenen Lehrbuch der Anatomie betätigt hat, in welchem er den Weg aufzeigte, wie eine viel stärker lebenswirkliche, das Bewegte und Bewegende in den Vordergrund rückende Morphologie anzupacken ist.» ${ }^{64}$

Braus trennte in seinem Lehrbuch Gestaltungsfunktionen von nicht formbildenden Betriebsfunktionen physikalisch-chemischer Art. Die Gestaltungsfunktionen veranschaulichte Braus durch experimentelle Methodik beim Embryo, vor allem aber am Bewegungsapparat des Erwachsenen. ${ }^{65}$

Bluntschli konzentrierte sich auf den Kiefer- und Kauapparat von Menschen und Menschenaffen und beschrieb beim Menschen ein Basalbogensystem. Es handelte sich dabei um Teile des Ober- und Unterkiefers, von denen Bluntschli glaubte, dass sie eine funktionelle Einheit bildeten, weil sie während der Entwicklung vom Embryo zum Erwachsenen erhalten bleiben

60 Bluntschli DMAP, Kap. II (Das Leben) 6 und Bluntschli GEE, S. Exp.7-8.

61 Bluntschli, H.: Das Problem der Homologie u. die vergleichende Anatomie (2.3.1922) (Ungedrucktes Vortragsmanuskript). In: FA BL, Mappe 91.

62 Braus, H.: Anatomie des Menschen. Springer, Berlin, 1921.

63 Strauss 1964, 9. Die Skizzen zu Bluntschlis funktionellem Lehrbuch befinden sich im anatomischen Institut der Universität Bern.

64 Bluntschli,H.: Die Kaumuskulatur des Orang-Utan und ihre Bedeutung für die Formung des Schädels. I. Teil: Das morphologische Verhalten. Morph. Jb. 63 (1929 I) 536.

65 Braus 1921,3-5. 
(Abb. 3). Als ursprünglich vererbte Struktur konnten an ihm epigenetische, funktionelle Anpassungen verdeutlicht werden. Aus Druckmechanismen der Zahnbogen zueinander erklärte Bluntschli verschiedene Zahnstellungen und Gaumenwölbungen, die spezielle Stellung der Zähne beim Kleinkind und das Wachstum der Zahnreihen mit zunehmendem Alter. An die Darstellung der Basalbogen schlossen sich Untersuchungen der Kaumuskeln während des individuellen Lebens an. Schliesslich beschrieb Bluntschli in ähnlicher Weise die Kaumuskelverhältnisse bei Menschenaffen, besonders beim Orang-Utan (Abb. 4) ${ }^{66}$

Hauptergebnis bildete die Herausarbeitung wesentlicher epigenetischer Entwicklungsfaktoren im Kiefer und Schädel: die Druck- und Spannungsverhältnisse zwischen den Basalbogen, die Muskularisierung der Kiefer und die Cerebralisation (Gehirnentwicklung) ${ }^{67} \mathrm{Im}$ Unterschied zu seinem Jochbogenmodell von 1911 erwies sich die Zahl möglicher Faktoren als grösser, die funktionelle Analyse wurde dementsprechend komplexer. Vor allem aber diente Bluntschli die Darstellung der einzelnen Entwicklungsmomente nicht mehr zur Klärung phylogenetischer Probleme. Diese verstärkte Loslösung von der rein vergleichenden Tätigkeit empfand Bluntschli selbst als einen der wesentlichsten Schritte seiner wissenschaftlichen Laufbahn. ${ }^{68}$

Die neovitalistische Begrifflichkeit zeigte sich in den Arbeiten über die Kiefer und die Kaumuskulatur der Menschenaffen gefestigt und bestimmte auch Bluntschlis Ansichten über die Vererbung. In «Schädel und Gebiss in ihren funktionellen Beziehungen» lehnte Bluntschli Morgans Vererbungsansichten als Prädestinationslehre ab. Im Gegensatz zu seinen früheren Bekenntnissen zu zufälligen, spontanen Prozessen konnte sich Bluntschli kaum mehr vorstellen, wie neue Erbeigenschaften (und damit zweckvolle neue morphologische Merkmale) durch zufällige Einwirkungen wie Mutationen zustande kommen sollten. ${ }^{69}$ Zwar stimmte er Morgan zu, dass Chromosomen und Gene im Zellkern für die Vererbung verantwortlich waren, doch glaubte er, dass sie nur die allgemeinen Richtlinien für die Entwicklung festsetzten und für ein allgemeines Gestaltungsvermögen oder eine Reaktionspotenz standen. Erst durch die weitere Entwicklung, welche im Austausch mit Um-

66 Bluntschli, H.: Die menschlichen Kieferwerkzeuge in verschiedenen Alterszuständen. Anat. Anz. 61, Erg.-H. (1926 I) 163-176. Bluntschli, H.: Rückwirkungen des Kieferapparates auf den Gesamtschädel. Z. zahnärztl. Orthop. 18 (1926 II) 57-80. Bluntschli 1929 I, 531-606. Bluntschli, H.: Die Kaumuskulatur der Menschenaffen (nach Untersuchungen beim Orang). Anat. Anz. 67, Erg.-H. (1929 II) 199-207. Bluntschli, H.: Die Kaumuskulatur eines neugeborenen Orang-Utan. Vjschr. Zahnheilk. 47 (1931 I) 10-21.

67 Bluntschli 1926 II, 68-72.

68 Strauss 1964, 9.

69 Bluntschli, H.: Organische Einheit [OA] (1934) 20. (Ungedrucktes Vortragsmanuskript). In: FA BL, Mappe 91. 
Abb. 3. Bluntschlis Basalbogensystem (gepunktet) beim Erwachsenen mit Druckwirkungen auf den Schädel (Pfeile). Aus: Bluntschli, H.: Schädel und Gebiss in ihren funktionellen Beziehungen, 1936, XLII.
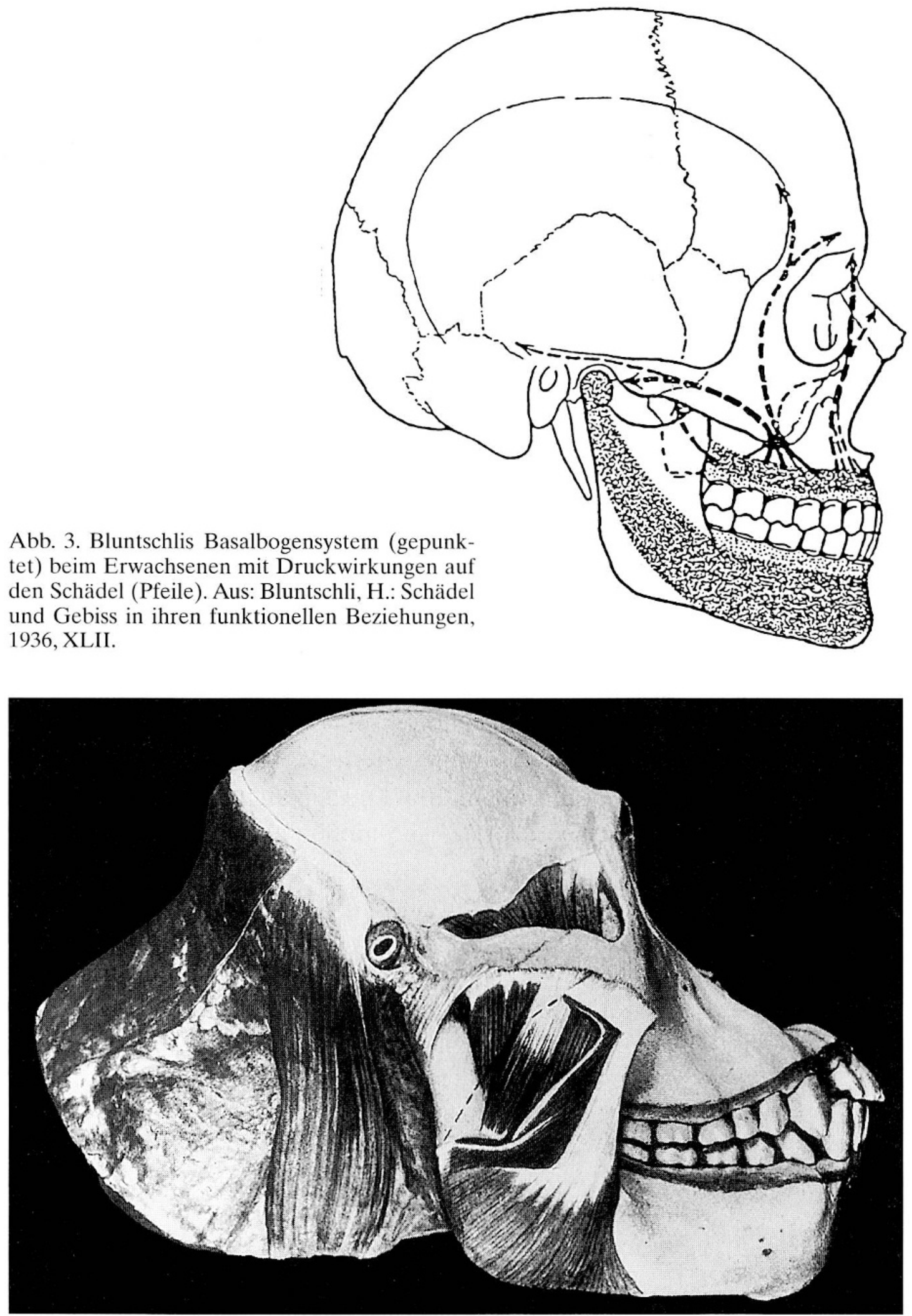

Abb. 4. Von Bluntschli angefertigtes Präparat eines Orang-Utan-Weibchens. Aus: Bluntschli, H.: Die Kaumuskulatur des Orang-Utan und ihre Bedeutung für die Formung des Schädels, 1929 II, Tafel V. 
welteinflüssen vor sich geht, entwickelt sich gemäss Bluntschli die exakte Struktur. ${ }^{70}$

Sollten solche Strukturen an der Artbildung beteiligt sein, mussten Umwelteindrücke in das Erbmaterial übergehen, was wiederum einer Vererbung erworbener Eigenschaften entsprach. Bluntschli stellte sich vor, dass jeder Organismus eine Art primitiven Einfühlungsvermögens besass, so dass Umwelteindrücke ähnlich Erinnerungen gespeichert und an die Nachkommen weitervererbt wurden. ${ }^{71}$ Er bezog sich dabei auf den Münchner Zoologen Richard Semon (1859-1918) und dessen Theorie eines biologischen Gedächtnisses, die Mnemetheorie. Die Mneme war die Summe aller aufgenommenen Engramme, Engramme wiederum aufgezeichnete Einwirkungen der Umwelt. Je nach Grad der Einwirkung wies ein Organismus ein stärkeres oder schwächeres Engramm auf. Die erworbenen Engramme wurden schliesslich vererbt. ${ }^{72}$ Mit diesem Mechanismus distanzierte sich Bluntschli deutlicher als mit seinen praktisch-funktionellen Arbeiten von der physikalisch-chemisch orientierten Biologie. Solcherart programmatische, naturphilosophische Begrifflichkeit kennzeichnete indessen viele Vertreter des NeoLamarckismus, so die Paläontologen Othenio Abel (1875-1946) und Otto Jaeckel (1863-1929), deren funktionelle Einteilungen der Kiefer eine experimentelle Grundlage für Bluntschlis Basalbogenmodell bildeten. ${ }^{73}$

\section{Grenzen der Funktionalität}

In Bluntschlis folgenden primatologischen Arbeiten zeigte sich neben der Funktionalität wieder eine vermehrte Betonung traditioneller Morphologie. Schon 1929 schien ihm bei einem Neuweltaffen eine funktionelle Analyse nicht durchführbar. Zu gross wurde wegen der vielen verschiedenen Lokomotionsarten der Primaten die Zahl funktioneller Faktoren. War eine funktionelle Deutung von Merkmalen nicht möglich, wollte Bluntschli bewusst traditionell-phylogenetische Interpretationsmodelle nicht ausschliessen. Im Unterschied zu früheren morphologischen Befunden sollten jedoch evolutionäre Deutungen eines Merkmals nicht zur Aufstellung eines Stammbaums dienen, sondern vor allem auf frühere Umweltbedingungen hinweisen, unter welchen das Merkmal durch funktionelle Anpassung erworben worden

70 Bluntschli, H.: Schädel und Gebiss in ihren funktionellen Beziehungen. Schweiz. med. Jb. (1936) XLVII, XLVIII.

71 Bluntschli OA, 21 und Bluntschli 1936, XLVII.

72 Schatzmann, J.: Richard Semon (1859-1918) und seine Mnemetheorie. Zürcher med. gesch. Abhandl. Nr. 58 (1968) 47-65.

73 Reif, W. E.: The Search for a Macroevolutionary Theory in German Palaeontology. J. hist. biol. 19 (1986) 111. Bluntschli, H.: Zur allgemeinen Gebisslehre [gemeinsam mit H. Schreiber]. Fortschr. Zahnheilk. 4 (1928) 3-8. 
war. So deutete Bluntschli einen im Verhältnis kräftiger ausgebildeten Nagel an der zweiten Zehe des Neuweltaffen schliesslich als ein von den Vorfahren her beibehaltenes altes Erbmerkmal und fügte den vergleichenden Hinweis an, dass sich dieses Merkmal auch bei Halbaffen zeige. ${ }^{74}$

Die erneute Wichtigkeit phylogenetischer Gesichtspunkte setzte sich in der Fertigstellung von Bluntschlis einziger Beschreibung fossiler Primaten fort, die 1931 kurz vor seiner Expedition nach Madagaskar veröffentlicht wurde. In der ausführlichen Erörterung der bereits achtzehn Jahre zuvor in Argentinien gesichteten Fossilien widersprach Bluntschli der Ansicht Florentino Ameghinos (1854-1911), dessen Bruder die Fossilien entdeckt hatte, dass Homunculus den gemeinsamen Vorfahren der Neu- und Altweltaffen und somit auch einen Vorfahren des Menschen darstellte. Bluntschli unterstrich den Cebidencharakter der Funde und sah in Homunculus patagonicus einen Vorfahren der südamerikanischen Nachtaffen. ${ }^{75}$

Von 1933 bis zur Herausgabe seiner eigenen Zeitschrift 1938 erschienen letzte primatologische Arbeiten Bluntschlis. Inzwischen an der Universität Bern, begann er, das reiche Material an Lemuren und Lemurenembryonen aus Madagaskar zu bearbeiten. 1935,1937 und 1938 erschienen Aufsätze über die Zunge der Lemuren. Bluntschli versuchte, die verschiedenen Zungentypen dieser Primaten funktionell zu deuten, was jedoch nur bei den Cheirogaleinen gelang. Er bezog daher die Strukturen erneut auf phylogenetisch alte, vererbte Merkmale. ${ }^{76}$ Arbeiten über Microcebus (Mausmaki) und Borstenigelembryonen erfuhren 1938 ebenfalls phylogenetische Interpretationen. ${ }^{77}$ Die weitere Bearbeitung des Primatenmaterials aus Madagaskar durch Bluntschlis zahlreiche Doktoranden in Frankfurt und Bern, vor allem Hans Schreiber (1901-1960), Robert Hans Goetz (geb. 1910) und Fritz Strauss (1907-1994), zeigt dasselbe Bild: neben funktionellen sind vergleichend-embryologische und vergleichend-anatomische Aspekte wichtig. ${ }^{78}$

Die gleichzeitige Betonung von funktionellen und phylogenetischen The-

74 Bluntschli, H.: Ein eigenartiges an Prosimierbefunde erinnerndes Nagelverhalten am Fuss von platyrrhinen Affen. W. Roux' Arch. Entw. Mech. 118 (1929 III) 1-10.

75 Bluntschli, H.: Homunculus patagonicus und die ihm zugereihten Fossilfunde aus den SantaCruz-Schichten Patagoniens. Morph. Jb. 67 (1931 II) 811-892.

76 Bluntschli, H.: Die Lyssa der Zunge bei Microcebus. Schweiz. med. Wschr. 65 (1935) 286. Bluntschli, H.: Weitere Erfahrungen über die Lemuridenzunge. Schweiz. med. Wschr. 67 (1937) 170. Bluntschli, H.: Die Sublingua und Lyssa der Lemuridenzunge. Bio-Morphosis 1 (1938 I) 127-149.

77 Bluntschli, H.: Frühe Entwicklungsstadien von Microcebus murinus. Bio-Morphosis 1 (1938 II) 333-334. Bluntschli, H.: Le développement primaire et la formation d'un placenta perforé très compliqué et du type labyrinthique chez Hemicentetes (En collaboration avec R. Goetz). Bull. Acad. malgache 20 (1938 III) 73-75.

78 Ein Verzeichnis aller Doktoranden Bluntschlis mit ihren jeweiligen Arbeiten findet sich bei Strauss 1964, 22-25. 
men sowie der häufige Bezug auf experimentelle Studien anderer Wissenschaftler charakterisiert Bluntschli erneut als Vermittler zwischen der traditionellen Morphologie und der experimentellen Embryologie. Immer befürchtete er die Einseitigkeit einer der beiden Forschungsrichtungen und vertrat eine Erweiterung der Einzeldisziplinen zu einer umfassenden Naturwissenschaft. Mit seiner Zeitschrift Bio-Morphosis wollte Bluntschli 1938 ein Forum methodischer Vielseitigkeit schaffen, indem er Aufsätze aus verschiedenen Bereichen der Biologie zu veröffentlichen hoffte. Sein Entwurf wissenschaftlicher Zusammenarbeit stiess jedoch auf wenig Interesse, und so wurde die Herausgabe der Zeitschrift bereits nach einem Jahr wieder eingestellt. ${ }^{79}$

\section{Bluntschli und die synthetische Evolutionstheorie}

Solange die Rolle chromosomaler Rekombinationsmechanismen im Prozess der Artbildung nicht geklärt war, bestanden weiterhin neo-lamarckistische Erklärungsmuster. ${ }^{80} \mathrm{Je}$ mehr empirische Belege die Genetiker jedoch über die Wirkungsweise von Chromosomen und Genen sammelten, desto schwieriger wurde es, einen ebenso plausiblen Mechanismus für eine Vererbung erworbener Eigenschaften zu finden. Spätestens mit der Formulierung der synthetischen Theorie der Evolution in den 1940er Jahren wurde deutlich, dass Gene keineswegs unabhängige Einheiten darstellten. Mathematiker, Genetiker und Zoologen zeigten, dass durch Kreuzungen in Kleinpopulationen Variationen stimuliert werden konnten. Die genetischen Mechanismen waren zusammen mit der natürlichen Selektion imstande, neue zweckmässige Merkmale auch ohne Vererbung erworbener Eigenschaften anzuhäufen. Zudem konnte dadurch ein Merkmal ohne unmittelbaren adaptiven Wert weiterhin im Genpool einer Population vorhanden bleiben. ${ }^{81}$

Bluntschli war über den Stand der Evolutionsforschung Anfang der 1940er Jahre exakt informiert. In einem Referat über das Buch Der Evolutionsprozess in seiner heutigen Fassung der deutschen Genetikerin Gertrud Haase-Bessel stellte er 1941 alle wesentlichen Punkte der neuen Genetik vor: Chromosomen, Mutationen, Unterschiede zwischen Mutationen und Modifikationen ohne Einfluss auf die Erbsubstanz, schliesslich den Artbildungsprozess durch natürliche Selektion, Isolation und genetischen Drift. ${ }^{82}$

79 Bluntschli, H.: Bio-Morphosis. Zur Einführung. Bio-Morphosis 1 (1938 IV) 1-4. Die Weiterführung der Zeitschrift Bio-Morphosis scheiterte unter anderem am Mangel eingereichter Manuskripte. Zur genaueren Darstellung siehe Greif 1991,67-71.

80 Reif 1986, 110-111.

81 Bowler 1989, 308-309, 313-314, 316-317.

82 Bluntschli, H.: Referat über Haase-Bessel: Der Evolutionsgedanke in seiner heutigen Fas- 
Trotzdem äusserte sich Bluntschli 1941 und 1942 in anderen Vorträgen und Vorlesungen weiterhin in neo-lamarckistischem Sinn und verknüpfte die verschiedenen theoretischen Ansätze in einer eigentümlichen Spannung. Die zufälligen Umgruppierungen der Gene bei den Befruchtungsvorgängen (Crossing-over etc.) zeigten gemäss Bluntschli auf, dass Gene morphologische Merkmale nicht exakt, sondern nur ungefähr bestimmten - analog seiner früheren Idee einer blossen Reaktionspotenz von Genen. Die Umwelteinflüsse wie genetischer Drift, Isolation und Mutationen belegten für Bluntschli nur die Tatsache einer allgemeinen Umwelteinwirkung. Äussere Bedingungen wirkten für ihn nach wie vor hauptsächlich mittels mnemischer Empfindungen auf die Organismen ein. ${ }^{83}$

Im Manuskript zur Vorlesung "Das Leben" vom Wintersemester 1941/42 in Bern stellte Bluntschli die Entwicklung der Organismen folgendermassen dar:

«Die Gleichartikeit des neu sich bildenden Organismus wurzelt dabei in der Beharrungstendenz seiner lebenden Substanz. Sie ist, grob genommen, überhaupt nur zur Leistung eines Wiederholungsgeschehens befähigt. Aber der neue Organismus ist dennoch keine absolute Replik, er gestaltete sich jeweils auch in Relation zu den gegebenen äusseren Entwicklungsbedingungen und aus diesen Beziehungen entspringt wenigstens ein Teil seiner besonderhaften Prägung.» ${ }^{84}$

Neue Merkmale entstanden in erster Linie in adaptiver Auseinandersetzung mit der Umwelt, während die Vererbung für die Weitergabe vorhandener Merkmale verantwortlich war. Die evolutionstheoretischen Manuskripte mit ihrem neo-lamarckistischen Gedankengut belegen damit, wie ähnlich Bluntschlis wissenschaftliche Grundlagen noch immer den Ansichten Carl Gegenbaurs waren. Damit wird verständlich, weshalb Bluntschli trotz der von ihm selbst als richtungsweisend angesehenen Hinwendung zu funktionellen Arbeiten methodisch immer ein vergleichender Morphologe und Primatologe blieb.

\section{Bluntschlis unvollendetes Werk}

Ein stetes Anliegen war Bluntschli zu verschiedenen Zeiten immer auch die Herausgabe eines grossen Lehrbuchs der Morphologie und Primatologie.

sung (1941) 33 (Ungedrucktes Vortragsmanuskript). In: FA BL, Mappe 92.3. Haase-Bessel, G.: Der Evolutionsgedanke in seiner heutigen Fassung. Gustav Fischer, Jena, 1941.

83 Bluntschli, H. über Ernst, A.: «Vererbung durch labile Gene» (1943) 5 (Ungedrucktes Vortragsmanuskript). In: FA BL, Mappe 92.

84 Bluntschli, H.: Das Leben (1941/42) 13 (Ungedrucktes Vorlesungsmanuskript). In: FA BL, Mappe 92. 
Doch wie beim funktionellen Lehrbuch der Anatomie kam Bluntschli dabei nicht über Vorarbeiten hinaus. Das umfangreiche, jedoch unveröffentlichte Manuskript «Der Mensch als Primate» stellte 1909/10 einen ersten Entwurf einer solchen umfassenden Darstellung dar. Bei der Begründung seiner Madagaskar-Expedition erwähnte Bluntschli das geplante Lehrbuch erneut. Mit einer Morphologie aller Primaten wollte er zu dieser Zeit eine gesicherte Basis für die genetische Richtung der Anthropologie bieten. ${ }^{85}$ Während er sich nach seiner Emeritierung aber noch intensiv der Zusammenstellung von Reisetagebüchern aus seinen Notizen und Briefen aus Südamerika und Madagaskar widmete ${ }^{86}$ und ein kleines anatomisches Lehrbuch veröffentlichte ${ }^{87}$, gelangte das primatologische Lehrbuch nicht mehr zur Ausführung. 1951 verkaufte Bluntschli den grössten Teil seiner Sammlung an das Museum of Natural History in New York und das Carnegie Institute of Washington in Baltimore. In der Begleitschrift zur Sammlung lassen sich schliesslich weitere Hinweise auf das unvollendete Primatenwerk finden:

«The long years of bitter European strife did not permit me to carry scientific investigation of this material as far as I had planned. Much has been done, under my guidance, by my assistants and pupils. Much, however, remains to be done, and I myself am too old to complete it. It is my wish that young investigators may continue the work successfully.» ${ }^{88}$

Neben politischen Aktivitäten im Umfeld Gottlieb Duttweilers (1888-1962) widmete sich Bluntschli in seinen letzten Lebensjahren dem morphologischen Verständnis Goethes (1749-1832) und historischen Themen ${ }^{89}$. In den 1970er Jahren schliesslich wurden Bluntschlis Sammlungsobjekte der Carnegie Institution an die University of California in Davis (Kalifornien, USA) überführt. Die übrigen Stücke von Bluntschlis Sammlung befinden sich im Museum of Natural History in New York, an der Universität Bern und der Universität Zürich.

85 Bluntschli, H.: Kurze Darstellung der leitenden Gesichtspunkte u. Programm einer geplanten morphologisch-embryologischen Studien- und Sammelreise nach Madagaskar im Jahre 1931 (1931) 5. (Ungedrucktes Manuskript). In: FA BL, Mappe 168.1.

86 Die je über dreihundertseitigen Manuskripte gelangten bisher ebenfalls nicht an die Öffentlichkeit. [Bluntschli, H.: Südamerikanische Reisebriefe (Erste Ausarbeitung des Tagebuchs. In: FA BL, Mappe 166. Bluntschli, H.: Tagebuch in Briefen (Ur-Fassung), (Madagaskar-Reise). In: FA BL, Mappe 171. Bluntschli, H.: Tagebuchnotizen der Madagaskarreise (Frühjahr 1950). Kopie im Besitz des anthropol. Instituts der Universität Zürich.]

87 Bluntschli, H.: Vademecum der Extremitäten-Anatomie. Erasmus-Verlag, München, 1947.

88 Bluntschli, H.: The Bluntschli Collection of primate and insectivore embryos. Carnegie Inst. Wash. Year n. 50 (1950/51) 160.

89 Bluntschli, H.: Goethe als Naturforscher und Biologe. Der Bund, Literatur- und Kunstbeilage, 5.8.1949. Bluntschli, H.: Die Lebenseinheit in Goethes Auffassung der Biologie. Neue Schweizer Rundschau (1950) 288-297. 


\section{Obituaries}

Die Schweizerische Gesellschaft für Geschichte der Medizin und der Naturwissenschaften trauert um den Verlust ihrer folgenden Mitglieder:

Herr Prof. Dr. Rudolf Bolliger, Seuzach

Herr Dr. Willem Frans Daems, Arlesheim

Herr Prof. Dr. Jonas Landmann, Binningen

Frau Kay Yvonne Trüb, Epalinges

\section{Willem Frans Daems}

3. Dezember 1911 bis 29. Dezember 1994

Willem Daems wurde in Amsterdam geboren, wo er Pharmazie studierte, 1938 das Apothekerdiplom erwarb und mit einer Arbeit über herzstärkende Drogen zum Doktor der Pharmazie promovierte. Seine ersten Schritte auf dem Gebiet der Pharmaziegeschichte widmete er genealogischen Studien einiger Amsterdamer Apothekerfamilien sowie der Pharmakopöeliteratur. Nach dem Krieg begann er ein Literatur- und Geschichtsstudium an der Universität Leiden. Daems hauptsächliches Arbeits- und Forschungsgebiet wurde rasch die mittelalterliche Pharmazie- und Medizingeschichte, ein Fach, welches der Verstorbene durch seine textkritische Kompetenz und seine lexikographischen Kenntnisse prägte. Nach 17 Jahren Bearbeitungszeit promovierte er 1967, diesmal an der Philosophischen Fakultät von Leiden, mit einer Arbeit über die niederländische medizinisch-pharmazeutische Literatur, die unter dem Titel «Boec van medicinen in Dietsche. Een Middelnederlandse compilatie van medisch-farmceutische literatuur» erschienen ist.

Nach kurzer Tätigkeit als praktischer Apotheker sowie einigen Jahren Arbeit in der Industrie in Leiden, wanderte Daems 1955 in die Schweiz aus, um die Stelle eines wissenschaftlichen Mitarbeiters, später des Leiters der Ärzteabteilung der Firma Weleda in Arlesheim zu übernehmen, eine Stellung, die ihm ermöglichte, zahlreiche Kurse und Vorträge im In- und Ausland zu geben. In Arlesheim setzte er seine schon in Holland begonnene Beschäftigung mit der Musik fort: Er gehörte zu den Gründern der «Freien Musikschule Basel» und trat in von ihm veranstalteten Konzerten in Arlesheim als 
Pianist auf. Sein berufliches Engagement für die Anthroposophie führte Daems zum Studium des Werkes von Paracelsus, zur Publikation verschiedener Aufsätze über Hohenheim, insbesondere in der Zeitschrift «Nova Acta Paracelsica», und zur Herausgabe einiger Werke, zum Beispiel das kurz vor seinem Tod erschienene «Denn der Himmel ist der Mensch und der Mensch ist der Himmel». Seit 1973 lehrte Daems Medizingeschichte an der Universität Würzburg. Zu seinem siebzigsten Geburtstag haben ihm seine Freunde und Kollegen eine Festschrift gewidmet: > Gelêrter der arzeniê, ouch apotêker $<$. Vor zwei Jahren hat Daems die Frucht seiner über Jahre dauernden Forschungen in ein Werk zusammengefasst, welches meisterhaft das Gebiet der Terminologie der mittelalterlichen Drogen umreisst.

Daems war auch in zahlreichen Gelehrtengesellschaften tätig. Als langjähriges Vorstandsmitglied der Schweizerischen Gesellschaft für Geschichte der Pharmazie wurde er 1980 deren Vizepräsident. 1986-1989 sass er der Schweizerischen Paracelsus-Gesellschaft vor. Er war ebenfalls Mitglied der American Medieval Society, und 1978 wurde er in die «Académie internationale d'histoire de la pharmacie» aufgenommen.

Die Welt der Medizin- und Pharmaziegeschichte verliert mit Willem Daems einen Forscher, dem es gelang, Akribie mit Offenheit und Leidenschaft zu verbinden.

François Ledermann

Eine ausführliche Würdigung von Willems Daems durch Prof. Dr. Gundolf Keil wird in den Würzburger medizinhistorischen Mitteilungen Bd. 13 (1995) erscheinen. In derselben Zeitschrift Bd. 9 (1991) 439-448 ist auch der zweite Teil der Bibliographie erschienen. Am ergiebigsten über Dr. Daems orientiert wohl die Festschrift von 1982, die als Band 24 der Würzburger medizinhistorischen Forschungen erschienen ist. 